\section{THU0632-HPR DETERMINANTS OF HAPPINESS AND QUALITY OF LIFE IN PEOPLE WITH SYSTEMIC SCLEROSIS: A STRUCTURAL EQUATION MODELLING APPROACH}

T. Santiago ${ }^{1,2}$, E. Santos $^{1,3}$, A. C. Duarte ${ }^{4}$, P. Martins ${ }^{5,6}$, M. Sousa $^{1}$,

F. Guimarães ${ }^{7}$, S. Azevedo ${ }^{7}$, R. Ferreira ${ }^{8}$, M. Guerra ${ }^{9}$, A. Cordeiro $^{4}$,

I. Cordeiro ${ }^{5,6}$, S. Pimenta ${ }^{8}$, P. Pinto ${ }^{9}$, M. J. Salvador ${ }^{1,2}$, J. A. P. Da Silva ${ }^{1}{ }^{1}$ Centro

Hospitalar e Universitário de Coimbra, Rheumatology, Coimbra, Portugal;

${ }^{2}$ University of Coimbra, Faculty of Medicine, Coimbra, Portugal; ${ }^{3} \mathrm{Health}$

Sciences Research Unit: Nursing, Nursing School of Coimbra, Coimbra,

Portugal; ${ }^{4}$ Hospital Garcia de Orta, Almada, Portugal; ${ }^{5}$ Hospital de Santa Maria, Centro Hospitalar Universitário Lisboa Norte, CHULN, Centro Académico de Medicina de Lisboa, Serviço de Reumatologia e Doenças Ósseas Metabólicas, Lisboa, Portugal; ${ }^{6}$ Unidade de Investigação em Reumatologia, Instituto de Medicina Molecular, Faculdade de Medicina, Universidade de Lisboa, Centro Académico de Medicina de Lisboa, Lisboa, Portugal; ${ }^{7}$ Unidade Local de Saúde Alto Minho, Ponte de Lima, Portugal; ${ }^{8}$ Centro Hospitalar Universitário São João, Porto, Portugal; ${ }^{9}$ Centro Hospitalar Vila Nova Gaia/Espinho, Vila Nova de Gaia, Portugal

Background: In recent years more attention has been given to patients reported outcomes (PROs). Systemic sclerosis (SSc) is no exception. As there is no effective treatment or cure to SSc, it is important to recognize the relevance to patients of the different features of the disease to improve quality and enjoyment of life: the ultimate targets of therapy. Remarkably lacking in PROs is the evaluation of the overall perspective of subjective well being, equivalent to 'happiness' or "positive psychological dimensions".

Objectives: To examine the determinants of happiness and quality of life (QoL) in patients with SSc with emphasis on disease activity, disease impact and personality traits.

Methods: This is an observational, cross-sectional and multicenter study from six rheumatology clinics in Portugal. A total of 113 patients with SSc with a complete set of data on disease activity, disease impact, personality, quality of life and happiness were included.

Structural equation modelling (latent variable structural model) was used to estimate the association between the variables using a maximum likelihood estimation with Satorra-Bentler's correction and performed with STATA $®$ 15.0. Two hypotheses were pursued: $\mathrm{H} 1$ - Disease activity and impact of disease are negatively associated to overall QoL and happiness; $\mathrm{H} 2$ - 'Positive' personality traits are related to happiness both directly and indirectly through perceived disease impact.

Results: Results obtained in the structural equation measurement model indicated a good fit $\left[x_{2} / \mathrm{df}=1.44 ; \mathrm{CFI}=0.93 ; \mathrm{TLI}=0.90 ; \mathrm{RMSEA}=0.06\right]$ and supported all driving hypotheses (Figure 1). Happiness was positively related to 'positive' personality $(\beta=0.45, p=0.01)$ and, to a lesser extent, negatively related with impact of disease $(\beta=-0.32 ; p=0.01)$. This impact, in turn, was positively related to EUSTAR activity score $(\beta=0.37 ; p<0.001)$ and mitigated by 'positive' personality traits $(\beta=-0.57 ; p<0.001)$. Impact of disease had a much stronger relation with QoL than with happiness $(\beta=-0.78, p<0.001)$. Quality of life and happiness had no statistically significant relationship.

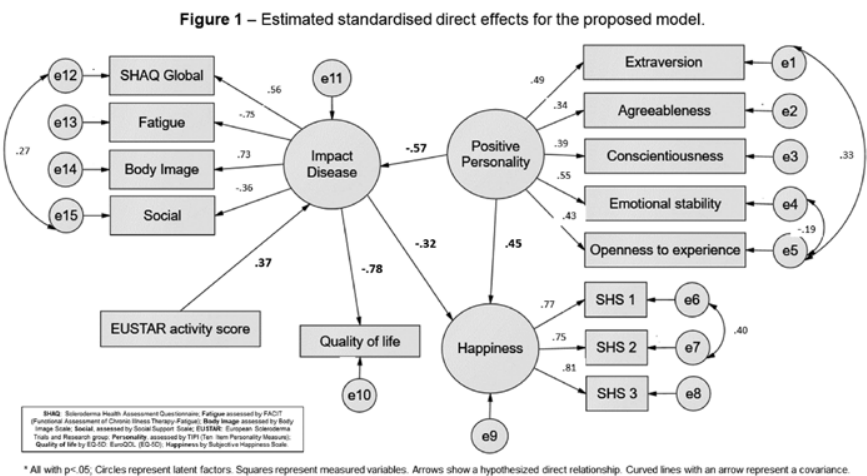

Conclusion: Optimization of Qol and happiness in people with SSc requires effective control of the disease process. Personality and its effects upon the patient's perception of the disease impact, seems to play a pivotal mediating role in these relations and should deserve paramount attention if happiness and enjoyment of life is taken as the ultimate goal of health care.

Disclosure of Interests: Tânia Santiago: None declared, Eduardo Santos: None declared, Ana Catarina Duarte: None declared, Patrícia Martins: None declared, Marlene Sousa: None declared, Franscisca Guimarães: None declared, Soraia Azevedo: None declared, Raquel Ferreira: None declared, Miguel Guerra: None declared, Ana Cordeiro Consultant of: Ana Cordeiro has acted as a consultant for Roche, Speakers bureau: Ana Cordeiro has received speaker fees from Boehringer Ingelheim, Lilly, and Vitoria, Inês Cordeiro: None declared, Sofia Pimenta: None declared, Patrícia Pinto: None declared, Maria Joao Salvador: None declared, José Antonio P. da Silva Grant/research support from: Pfizer Abbvie, Consultant of: Pfizer, AbbVie, Roche, Lilly, Novartis DOI: 10.1136/annrheumdis-2020-eular.3946

\section{THU0633-HPR CORE MUSCLE ENDURANCE IN PATIENTS WITH ANKYLOSING SPONDYLITIS}

D. C. Saraç ${ }^{1}$, S. Bayram ${ }^{1}$, N. G. Tore ${ }^{1}$, F. Sari ${ }^{1}$, D. Oskay ${ }^{1}$, A. Avanoğlu Güler ${ }^{2}$,

A. Tufan ${ }^{2}{ }^{1}$ Gazi University, Physiotherapy and Rehabilitation, Ankara, Turkey;

${ }^{2}$ Gazi University, Internal Medicine, Ankara, Turkey

Background: It is stated that the muscles responsible for spinal stability around the trunk show long-term activity at low intensity in daily life, therefore, endurance insufficiency can cause loss of functionality and spinal stabilization and may induce pain (1).

Objectives: The primary purpose of this study was to compare the core muscle endurance of individuals with AS with the core muscle endurance of healthy individuals. The secondary aim of the study was to examine the association between core muscle endurance and balance, disease activity, spinal mobility, functional status, physical activity level and fatigue in individuals with AS.

Methods: The research is a cross-sectional study. 41 patients with AS and 40 healthy controls were included in the study. The core muscle endurance of both groups was assessed with trunk extension test, trunk flexion test, righ and left side plank tests (2). In addition, in the AS group relationship between core endurance and balance, thoracic kyphosis angle, disease activity, functionality, spinal mobility, physical activity and fatigue was examined. Balance was evaluated with BIODEX Balance Systems and thoracic kyphosis angle was evaluated with a digital inclinometer. Bath Ankylosing Spondylitis Disease Activity Index (BASDAI), Bath Ankylosing Spondylitis Functional Index (BASFI), Bath Ankylosing Spondylitis Metrology Index (BASMI), International Physical Activity Questionnaire (IPAQ), Fatigue Severity Scale (FSS) were used to assess disease activity, functionality, spinal mobility, physical activity and fatigue respectively.

Results: Significant differences were found between AS group and control group in core endurance were summarized in Table 1. Additionally, significant relationships were observed between core endurance and all the assessed parameters except thoracic kyphosis angle $(p<0.05)$, (Table 2$)$.

Table 1. Comparision of Core Endurance between AS and Control Groups

\begin{tabular}{lcccc}
\hline & $\begin{array}{c}\text { AS Group (n=41) } \\
\text { Median (IQR) }\end{array}$ & $\begin{array}{c}\text { Control Group (n=40) } \\
\text { Median (IQR) }\end{array}$ & $P$ \\
\hline Trunk Extensor Test (sec) & $44.0(12.0-77.5)$ & $98.25(63.75-120.0)$ & $<0.001$ \\
Trunk Flexor Test (sec) & $41.0(15.0-66.0)$ & $93.0(55.85-120.0)$ & $<0.001$ \\
Dominant Side Plank Test (sec) & $29.0(9.8-62.0)$ & $43.27(28.57-68.25)$ & $\mathbf{0 . 0 4 6}$ \\
Non-Dominat Side Plank Test (sec) & $32.0(10.0-61.32)$ & $41.25(25.0-62.37)$ & 0.092 \\
\hline
\end{tabular}

p>0.05, Mann-Whitney U Test; AS: Ankylosing Spondylitis, IQR: Interquartile Range sec: seconds

Table.2 Association between core endurance and other parameters

\begin{tabular}{|c|c|c|c|c|}
\hline & $\begin{array}{c}\text { Trunk Extensor } \\
\text { Test }\end{array}$ & $\begin{array}{c}\text { Trunk Flexor } \\
\text { Test }\end{array}$ & $\begin{array}{l}\text { Dominant Side } \\
\text { Plank Test }\end{array}$ & $\begin{array}{l}\text { Non-Dominant } \\
\text { Side Plank Test }\end{array}$ \\
\hline Pain (VAS) & $-0.535^{\star}$ & $-0.339^{*}$ & $-0.369^{*}$ & -0.203 \\
\hline Stiffness (VAS) & $-0.496^{*}$ & -0.234 & $-0.377^{\star}$ & 0.224 \\
\hline Overall Stability & $-0.480^{\star}$ & $-0.488^{\star}$ & $-0.725^{\star}$ & $-0.702^{\star}$ \\
\hline \multicolumn{5}{|l|}{ Index } \\
\hline BASFI & $-0.505^{\star}$ & $-0.441^{*}$ & $-0.562^{\star}$ & $-0.574^{*}$ \\
\hline BASMI & $-0.587^{\star}$ & $-0.390^{*}$ & $-0.613^{*}$ & $-0.501^{*}$ \\
\hline BASDAI & $-0.468^{\star}$ & -0.202 & $-0.433^{\star}$ & $-0.345^{\star}$ \\
\hline Kyphosis Angle( $\left.{ }^{\circ}\right)$ & -0.262 & -0.287 & -0.215 & -0.258 \\
\hline IPAQ & $-0.354^{\star}$ & $-0.355^{*}$ & $-0.523^{\star}$ & $-0.451^{\star}$ \\
\hline FSS & $-0.545^{\star}$ & $-0.445^{\star}$ & $-0.542^{\star}$ & $-0.502^{\star}$ \\
\hline
\end{tabular}

*: Spearman's Correlation Coefficient (rho), p<0.05; VAS: Visual Analog Scale, BASDAI: Bath Ankylosing Spondylitis Disease Activity Index, BASFI: Bath Ankylosing Spondylitis Functional Index, BASMI: Bath Ankylosing Spondylitis Metrology Index, IPAQ:International Physical Activity Questionnaire, FSS: Fatigue Severity Scale

Conclusion: Core muscle endurance is lower in patients with AS and it is in relation with many factors regarding the disease. The use of these tests may provide additional information about the patients' situation for clinicians. 